\title{
ANÁLISE DA SENSITIZAÇÃO DE JUNTAS SOLDADAS EM AÇO INOXIDÁVEL FERRÍTICO COM SOLDA DE ARAME TUBULAR MONOESTABILIZADO E BIESTABILIZADO AO NIÓBIO E TITÂNIO.
}

\author{
Gabriela Ferlin Gonçalves ${ }^{1}$; Susana Marraccini Giampietri Lebrão²; José Agustin Castillo \\ Lara $^{3}$; Marco Antônio Colosio ${ }^{4}$. \\ 1: Estudante Barechal em Eng. Mecânica, Instituto Mauá de Tecnologia, SP, SP, Brasil. \\ 2: Prof. ${ }^{a}$ Dr. ${ }^{a}$ de Eng. de Materiais, Instituto Mauá de Tecnologia, SCS, SP, Brasil. \\ 3. Prof.Me. Coordenador de Engenharia de Materiais e Soldagem, Centro Universitário \\ Fundação Santo André, Santo André, SP, Brasil. \\ 4: Engenheiro Bacharel em Eng. Mecânica, General Motors do Brasil, SCS, SP, Brasil.
}

\begin{abstract}
E-mails: gabriela.ferlin@ hotmail.com, susana.lebrao@maua.br, jose.lara@fsa.br, marco.colosio@gm.com.
\end{abstract}

\section{RESUMO}

O presente trabalho visa estudar o comportamento de aços inoxidável AISI 409 presentes no sistema de exaustão automotivo, passível de sensitização e falha durante processo de soldagem por arame tubular de AWS 5.9 EC 439 e também os efeitos benéficos da estabilização por titânio e da biestabilização. Para isso foram feitas análises metalograficas com Vilela, ensaio de corrosão com ácido oxálico e verificação das propriedades mecânicas na zona termicamente afetada e da zona fundida pelo ensaio de tração. Tanto as juntas soldadas com arame monoestabilizado quanto biestabilizado obtiveram bons resultados nos ensaios metalográficos, não apresentando precipitação de fases importante nem sensitização. As amostras romperam no metal base, mantendo suas propriedades mecânicas. As amostras soldadas com arame monoestabilizado apresentaram aumento do tamanho de grão tanto na zona termicamente afetada quanto na zona fundida, sendo que o aumento no tamanho de grão resulta em diminuição da tenacidade, ensaio que não foi realizado nesse trabalho. Grãos mais finos foram observados na solda biestabilizada, característica conferida pelo $\mathrm{Nb}$ na microestrutura, devido sua capacidade de conter o tamanho do grão. Quanto à suscetibilidade a corrosão intergranular, pode-se observar que em ambas as condições de soldagem, com arame tubular monoestabilizado e biestabilizado, não houve sensitização das amostras.

\section{INTRODUÇÃO}

Devido à competitividade do mercado automobilístico, cada vez mais as empresas procuram melhorar a qualidade e durabilidade de seus produtos. Nota-se que, entre os danos mais comumente observados no sistema de exaustão de veículos automotores, $80 \%$ são atribuídos à corrosão e os $20 \%$ restantes à fadiga ${ }^{[1]}$.

Como resultado desse levantamento o aço inoxidável vem sendo muito utilizado devido sua notória resistência à corrosão.Seu elemento de liga predominante é o $\mathrm{Cr}$, com pelo 
menos $11 \%$ em sua composição, e é o responsável pela formação de uma camada passiva sobre o material que o torna resistente à corrosão, aumenta a resistência à descamação, ao desgaste e à tração. As propriedades mecânicas do mesmopodem ser melhoradas com a adição de alguns elementos tais como níquel (Ni), nióbio (Nb), titânio (Ti) e molibdênio(Mo) ${ }^{[2]}$.

Nos aços inoxidáveis austeníticos o campo de fase austenita é estendido até a temperatura ambiente. Estes aços são conhecidos por serem os mais resistentes à corrosão devida sua alta concentração de cromo e também devido a adições de níquel, e são facilmente diferenciados das outras classes por não serem magnéticos. Possuem estrutura cúbica de face centrada (CFC), excelente ductilidade, resistência à corrosão, dureza, formabilidade e ótimo acabamento. Em contrapartida seu custo é maior que dos outros aços inoxidáveis, além de possuir baixo coeficiente de elasticidade e alto coeficiente de expansão térmica, consequentemente os aços inoxidáveis ferríticos estão os substituindo nos sistemas de exaustão veícular.São utilizados usualmente em equipamentos para processos químicos e de alimentos, vasos criogênicos e construções com solda [2],[3].

Os aços inoxidáveis ferríticos são compostos pela fase ferrita, com estrutura cúbica de corpo centrado (CCC); possuem boa ductilidade, assim, formabilidade, menor custo em comparação com os outros aços inox e resistentes a corrosão e oxidação ${ }^{[4]}$. Limitados pela tração, não devem ser usados em operações onde a dureza é importante, e geralmente menos resistentes à corrosão, também com menor alongamento, tenacidade, ductilidade que os aços inox austeníticos ${ }^{[1]}$.São comumente utilizados em componentes de exaustão automotivos, tanques para pulverizadores agrícolas, válvulas sujeitas a altas temperaturas, moldes para vidro e câmaras de combustão [2] [3].

Neste trabalho a união das juntas de aço inoxidável ferrítico é feita por solda de arame tubular com aço AISI 439estabilizado ao titânio e biestabilizado. A combinação de titânio e nióbio é denominada biestabilização.

Segundo Ferreira Filho (2010) [5] os primeiros precipitados da estabilização com Ti, em função da temperatura, são $\mathrm{TiO}_{2}$, seguido pelo TiN, e após a formação desses óxidos e nitretos aparecem os sulfetos $\left(\mathrm{Ti}_{1-\mathrm{x}} \mathrm{S}\right)$ e os carbosulfetos $\left(\mathrm{Ti}_{4} \mathrm{C}_{2} \mathrm{~S}_{2}\right)$ que se decompõe em sulfetos $(\mathrm{MnS})$ e carbonetos $(\mathrm{TiC})$. Se ainda existir Ti disponível, tem-se a formação de FeTiP. Os aços estabilizados com Ti têm modificações nas suas propriedades, como aumento da resistência mecânica por endurecimento por solução sólida, diminuição da ductilidade e aumento da temperatura de transição dúctil frágil. O tamanho dos precipitados ainda reduz a tenacidade ao impacto.

Já com a biestabilização com titânio e nióbio há somatória de características de ambos os elementos minimizando os problemas que apenas um causaria isolado. Os precipitados que se formam são primeiro os de titânio, $\mathrm{TiO}_{2}$, TiN, os sulfetos e carbosulfetos de Ti e quando não há mais deste disponível são formados carbonetos e carbonitretos de $\mathrm{Nb}$, caso também haja disponível $\mathrm{Nb}$ ocorre a formação da fase de Laves $\left(\mathrm{Fe}_{2} \mathrm{Nb}\right)$, esta fase intermetálica é responsável pela inibição do aumento do tamanho do grão.

Estes elementos são adicionados para que haja a precipitação de carbonetos e nitretos de titânio e nióbio, no lugar dos de cromo. Esses são mais estáveis e só se dissolvem na matriz 
ferrítica atemperaturas muito altas $\left(1200^{\circ} \mathrm{C}\right)$, superiores das do cromo ${ }^{[6]}$. Esta preferência ocorre devido aos carbonetos e nitretos de cromo ter potencial gamagênico, que é a capacidade de estender o campo austenítico para aços inox com altas porcentagens de cromo [5], [7].

A consequência da extensão do campo austenítico é que para peças que trabalham a altas temperaturas há a formação de austenita e consequentemente a formação de martensita nos contornos de grão no processo de resfriamento. Esta martensita possui características como baixa ductilidade e tenacidade, que resultam na fragilização da solda. Outros fatores que geram essa fragilização são a granulação grosseira nas regiões termicamente afetadas e fundidas e a fragilização a alta temperatura, consequência da alta reprecipitação de carbonitreto [5].

A soldagem é o processo de união de materiais usada para obter coalescência (união) localizada dos metais e não metais, produzida por aquecimento até uma temperatura adequada, com ou sem a utilização de pressão e/ou material de adição.

Algumasdas vantagens na utilização da solda é a possibilidade de construir peças complexas e unir materiais de alta resistência mecânica sem perda de propriedades na região soldada. Na prática, manter essas propriedades pode ser complicado devido à sensitização e a formação de martensita nos contornos de grão, como já foi mencionada anteriormente.

Devido à sensitização, o aço inoxidável ferrítico possui tendência à corrosão intergranular, resultado das variações térmicas ocorridas durante a soldagem. Esta é a propensão à corrosão localizada em contornos de grão advinda da precipitação de carbonetos de cromo; formando assim, uma região empobrecida de cromo que é suscetível a corrosão [8] [9] ${ }^{[10]}$.Por este motivo que também é realizada a adição de $\mathrm{Ti}$ e $\mathrm{Nb}$ no material, como mencionado acima, estes roubam o carbono e o nitreto impedindo a formação dos carbonetos e nitretos de cromo.

Segundo a norma ASTM A763 ${ }^{[11]}$ os aços inoxidáveis ferríticos estarão suscetíveis à corrosão intergranular quando apresentarem contornos de grãos valetados ou com "ditches", ou seja, completamente envolvidos pela corrosão, conforme Figura 1.

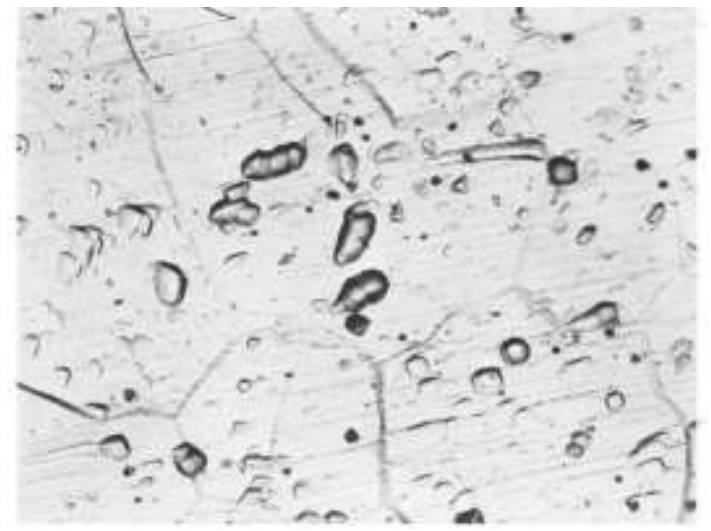

(a)

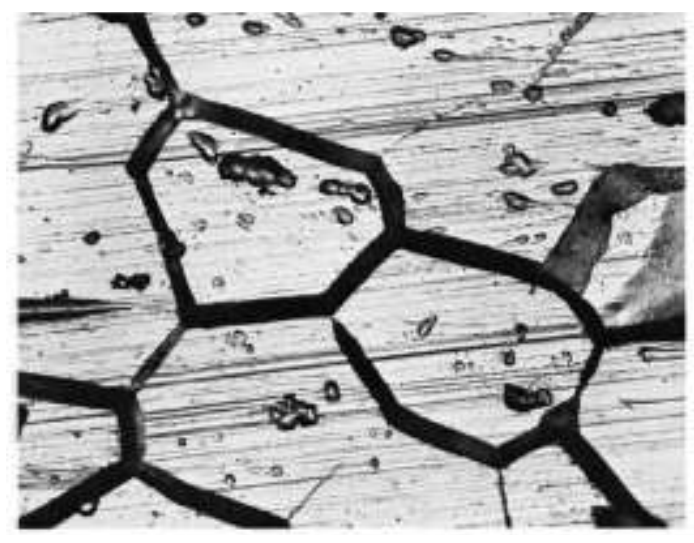

(b)

Figura 1- Norma ASTM A763 ${ }^{[11]}$ (a) Estrutura aceitável de aço inoxidável ferrítico após ensaio (b) Estrutura inaceitável, apresentando corrosão intergranular, de aço inoxidável ferrítico após ensaio. 


\section{MATERIAIS E MÉTODOS}

Na Tabela 1 é apresentada a composição química do material de base que é aço inoxidável ferrítico AISI409, Acesita, nas Tabelas 2 e 3 a composição dos arame de solda mono estabilizado SELECT arc (SELECT 439Ti) e arame de solda biestabilizado Kestra KST TUB $439 \mathrm{G}$.

Tabela 1 - Composição química doaço inoxidável ferrítico AISI 409

\begin{tabular}{|c|c|c|c|c|c|c|c|c|c|c|c|}
\hline AISI & DIN & $\mathrm{C}$ & $\mathrm{Mn}$ & $\mathrm{Si}$ & $\mathrm{P}$ & $\mathrm{S}$ & $\mathrm{Cr}$ & $\mathrm{Ni}$ & $\mathrm{Mo}$ & $N_{2}$ & Outros \\
\hline 409 & 1.4512 & 0,03 & 1,00 & 1,00 & 0,04 & 0,02 & $\begin{array}{c}10,5 \\
\mathrm{a} \\
11,7\end{array}$ & 0,5 & - & 0,030 & $\begin{array}{c}6\left(\mathrm{C}+N_{2}\right) \\
<=\mathrm{Ti} \\
<=0,50\end{array}$ \\
\hline
\end{tabular}

Tabela 2 - Composição química do arame tubular 430 Ti - monoestabilizado

\begin{tabular}{|c|c|c|c|c|c|c|c|}
\hline AISI & $\mathrm{C}$ & $\mathrm{Mn}$ & $\mathrm{P}$ & $\mathrm{S}$ & $\mathrm{Si}$ & $\mathrm{Cr}$ & $\mathrm{Ti}$ \\
\hline $439 \mathrm{Ti}$ & 0,02 & 0,68 & 0,010 & 0,010 & 0,56 & 17,90 & 0,80 \\
\hline
\end{tabular}

Tabela 3 - Composição química do arame tubular 430 Ti e Nb - biestabilizado

\begin{tabular}{|c|c|c|c|c|c|c|c|c|c|c|c|}
\hline $\mathrm{AISI}$ & $\mathrm{C}$ & $\mathrm{Mn}$ & $\mathrm{Si}$ & $\mathrm{P}$ & $\mathrm{S}$ & $\mathrm{Cr}$ & $\mathrm{Mo}$ & $\mathrm{Cu}$ & $\mathrm{Ni}$ & $\mathrm{Ti}$ & $\mathrm{Nb}$ \\
\hline 439 & $<$ & $<$ & $<$ & $<$ & $<$ & 17,0 & $<$ & $<$ & $<$ & $10 \mathrm{x}$ & $10 \mathrm{xC}$ \\
$\mathrm{Ti}$ & 0,03 & 0,80 & 0,80 & 0,03 & 0,03 & - & 0,50 & 0,75 & 0,60 & $\mathrm{C}-$ & $-0,6$ \\
$\mathrm{Nb}$ & & & & & & 19,0 & & & & 1,1 & \\
\hline
\end{tabular}

Para ambos a confecção das juntas soldadas, fornecidas pela GM, foi realizada com argônio contendo 2 a 5\% de oxigênio, corrente direta, polaridade positiva, vazão de gás de 15 a $20 \mathrm{~L} / \mathrm{min}$ e comprimento de solda de 15 a $20 \mathrm{~mm}$. Os parâmetros de soldagem são apresentados na tabela 4 .

Para isso foram realizadas análises metalográficas e ensaios de tração em duas amostras diferentes, ambas com mesmo material base AISI 409 e cada uma com um tipo de arame de solda. Amostra 1 arame de solda AISI 439 Ti e amostra 2 arame de solda AISI 439 $\mathrm{Ti} \mathrm{Nb}$.

Tabela 4 -Parâmetros da condição de soldagem.

\begin{tabular}{|c|c|c|}
\hline Aço inoxidável & AISI 439 Ti & AISI 439 Ti e Nb \\
\hline Amperagem $(\mathrm{A})$ & 200 & 180 \\
\hline Velocidade de soldagem $(\mathrm{mm} / \mathrm{s})$ & 24 & 22 \\
\hline Voltagem $(\mathrm{V})$ & 20,5 & 21,0 \\
\hline
\end{tabular}


Os ensaios de tração foram realizados com cinco corpos de prova para cada tipo de junta soldada, segundo a norma ASTM A370 [12] sendo que os corpos de prova foram confeccionados obedecendo às especificações da mesma. $\mathrm{O}$ ataque metalográfico foi realizado com Vilela possibilitando boa visualização dos grãos da amostra, mostrando com nitidez as áreas termicamente afetadas e fundidas. $\mathrm{O}$ preparo de todas as amostras para a metalografia se deu pelo lixamento com as lixas d'água A220, A320, A400 e por fim A600, em seguida polimento com pasta de diamante de $1 \mu \mathrm{m}$. Por fim as amostras foram atacadas e avaliadas com um microscópio óptico.

As amostras foram avaliadas quanto a sua suscetibilidade à corrosão intergranular pelo ataque eletrolítico em ácido oxálico $10 \%\left(\mathrm{H}_{2} \mathrm{C}_{2} \mathrm{O}_{4} \cdot 2 \mathrm{H}_{2} \mathrm{O}\right)$, realizado com base na norma ASTM 763 [11].

\section{RESULTADOS E DISCUSSÕES}

Os resultados dos ensaios metalográficos podem ser observados nas Figuras 2 a 4 . Na Figura 2 pode-se observar que o metal base apresenta precipitação discreta como esperado em um aço estabilizado e grão refinado, tanto com ataque de Vilela, Figura2a, quanto em ácido oxálico, Figura 2b.

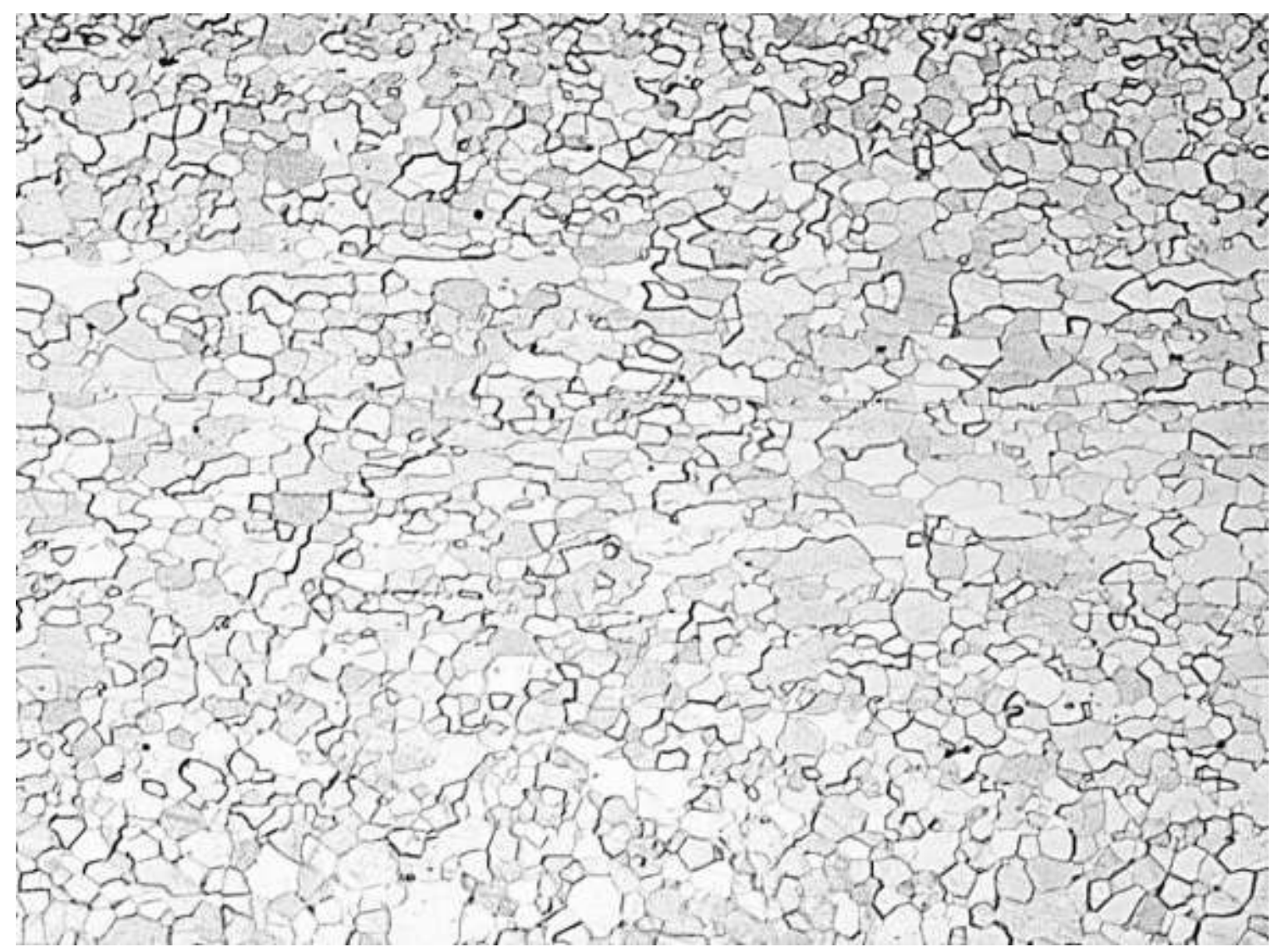




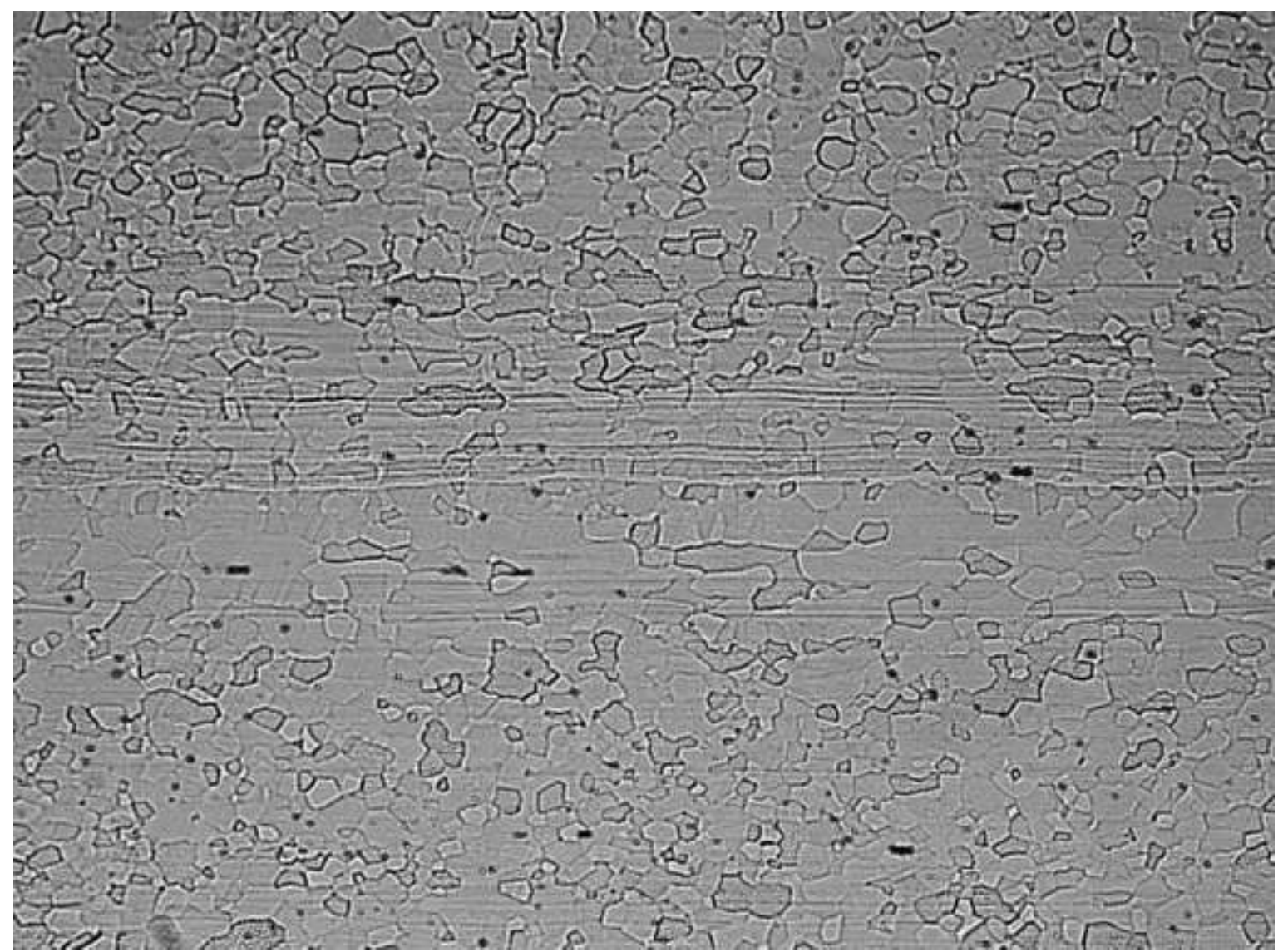

b)

Figura 2 - Metalografia do aço AISI 409, metal base, com aumento de 100x. a) Reagente Vilella; b) Ácido oxálico.

Nas Figuras 3 e 4 são apresentadas as metalografias das juntas soldadas referentes à zona fundida (ZF) a zona termicamente afetada (ZTA) e o metal base (MB), com ataque de Vilella e acido oxálico, respectivamente.

Pode-se observar o aumento do tamanho do grão na zona termicamente afetada e na zona fundida tanto para as amostras soldadas com arame monoestabilizado, Figura3e, quanto biestabilizada $\mathrm{Ti}$ e $\mathrm{Nb}$, em comparação com o metal base. Também foi possível notar um maior aumento no tamanho dos grãos das regiões termicamente afetadas e fundidas para as amostras com arame monoestabilizado, Figuras 3a e 3c, em comparação com as amostras soldadas com arame biestabilizado, Figuras $3 \mathrm{~b}$ e $3 \mathrm{~d}$. 


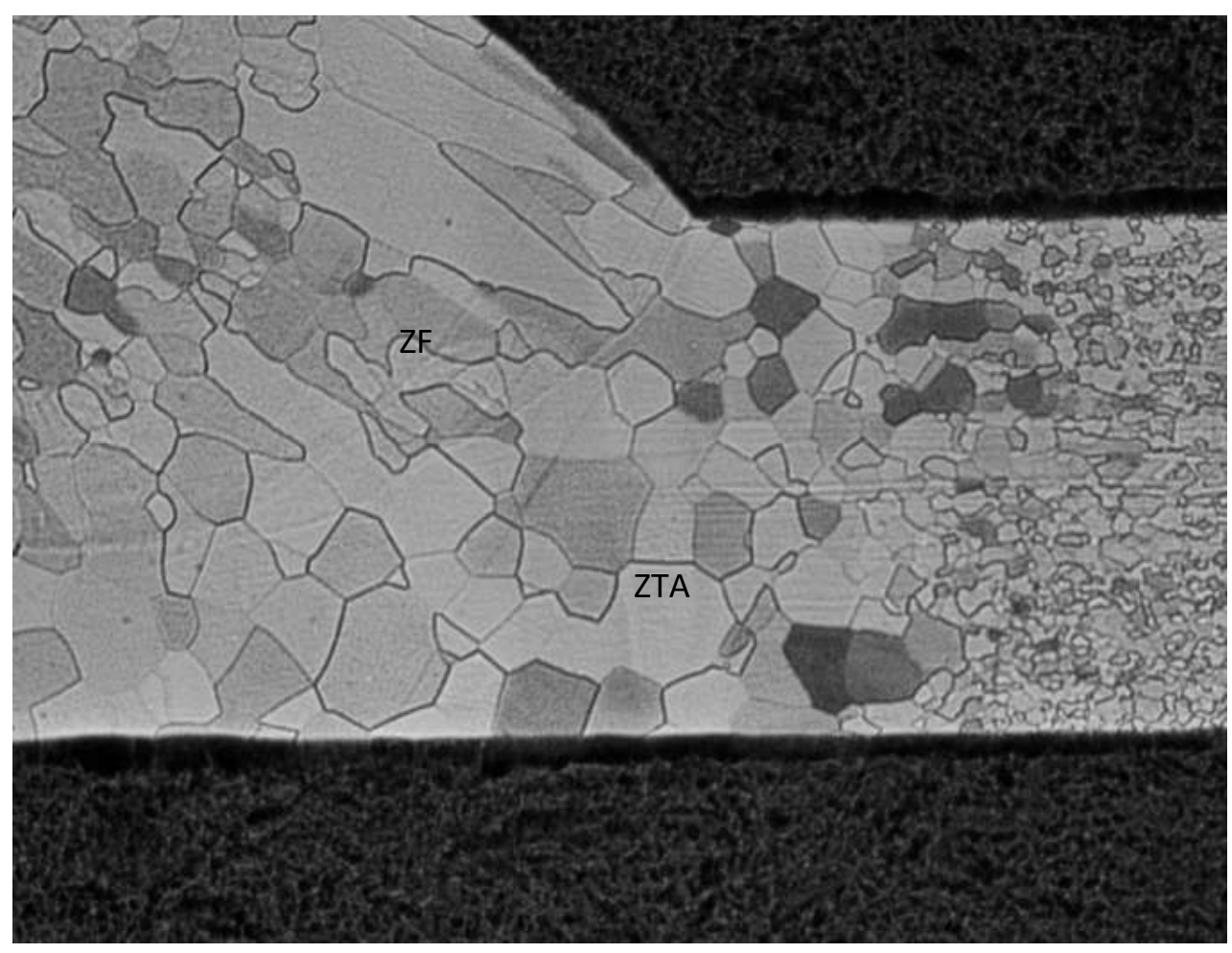

a)

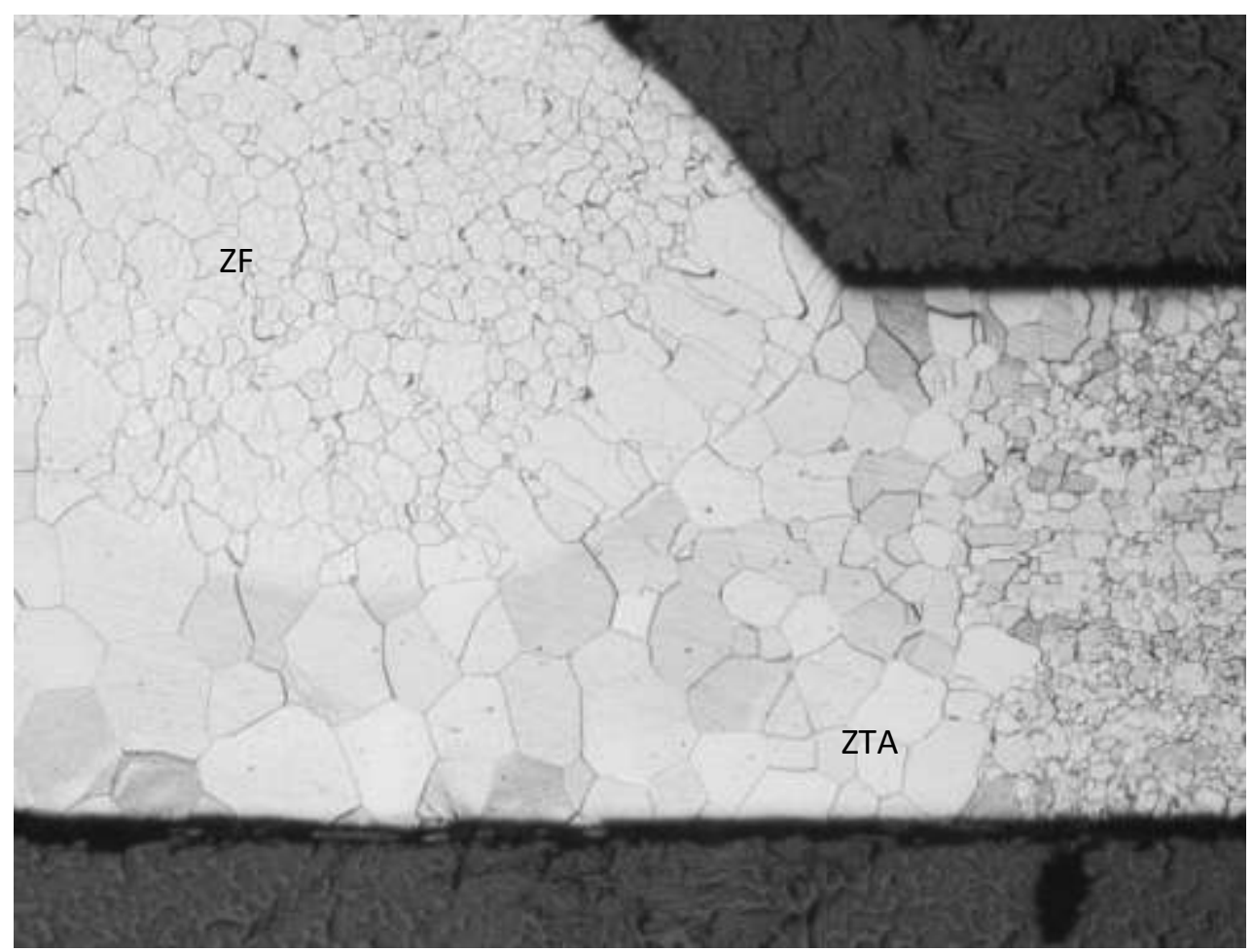

b) 


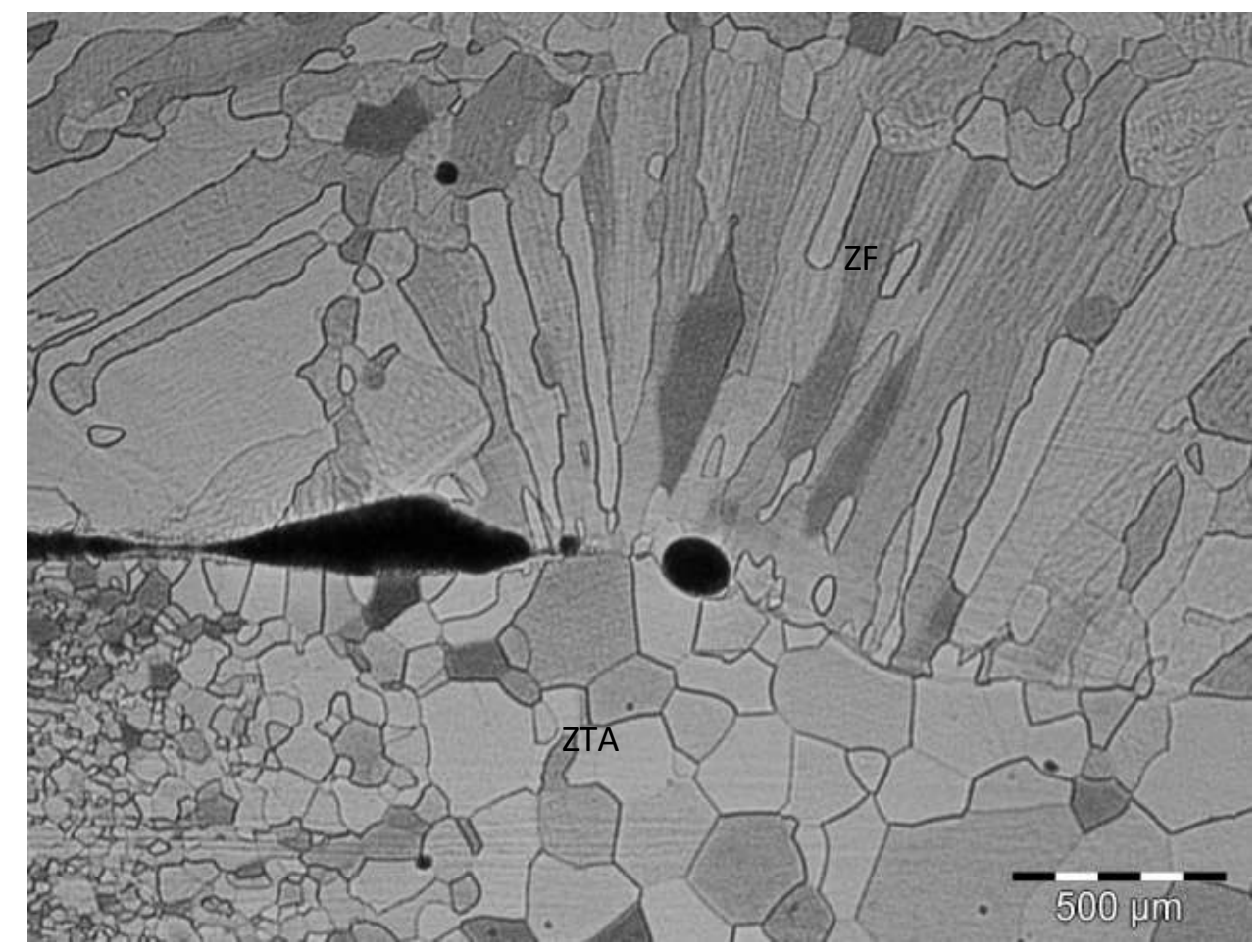

c)

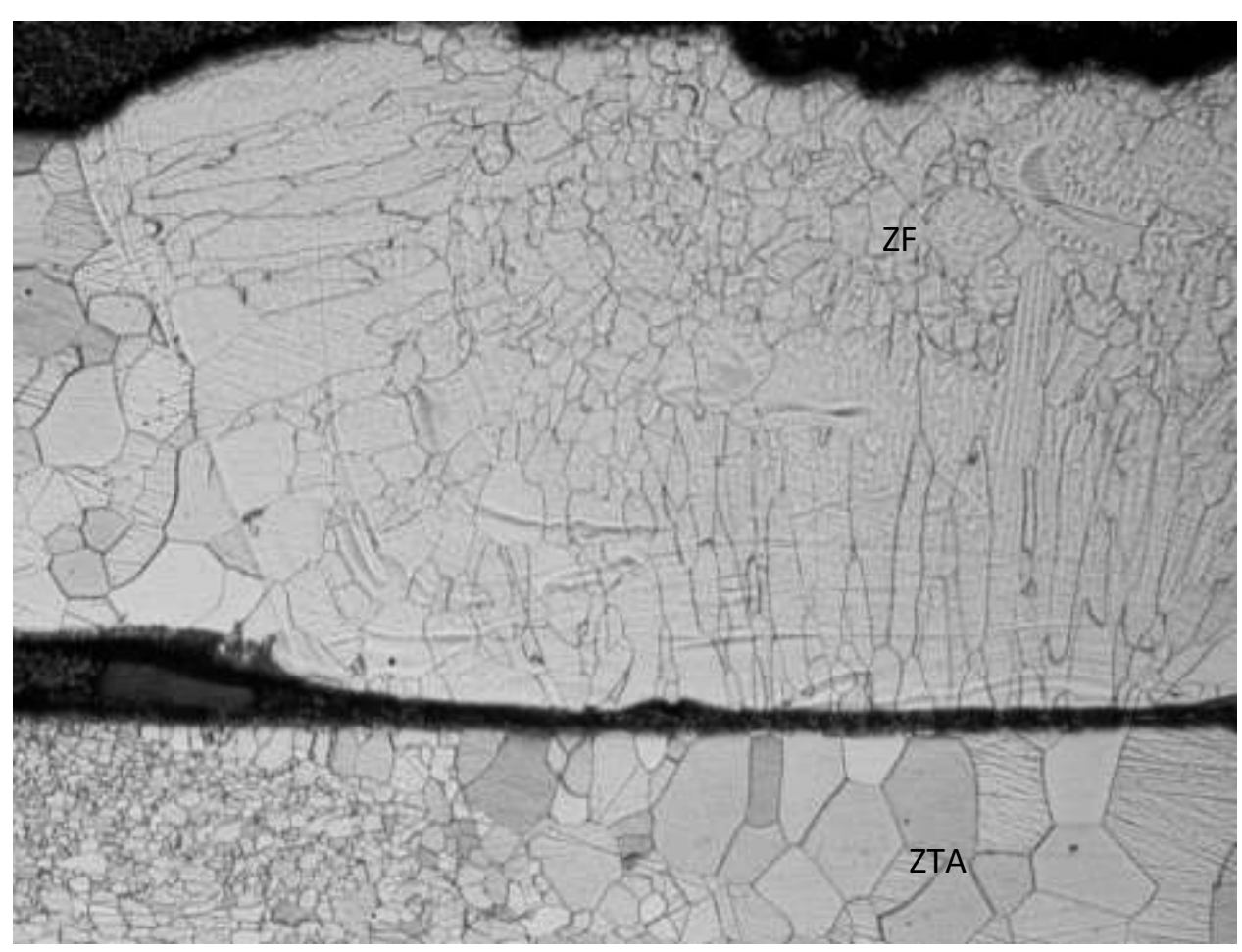

d) 


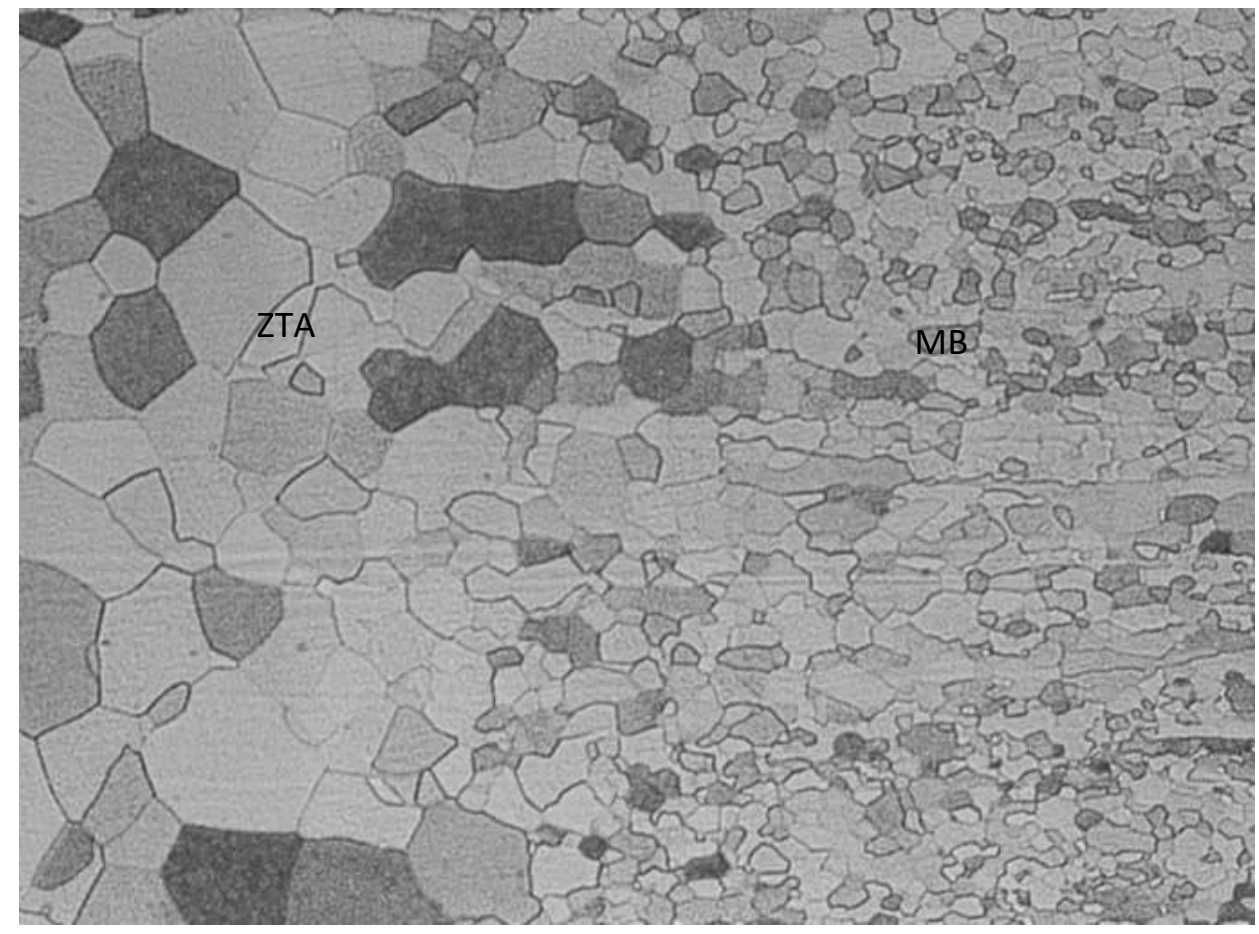

e)

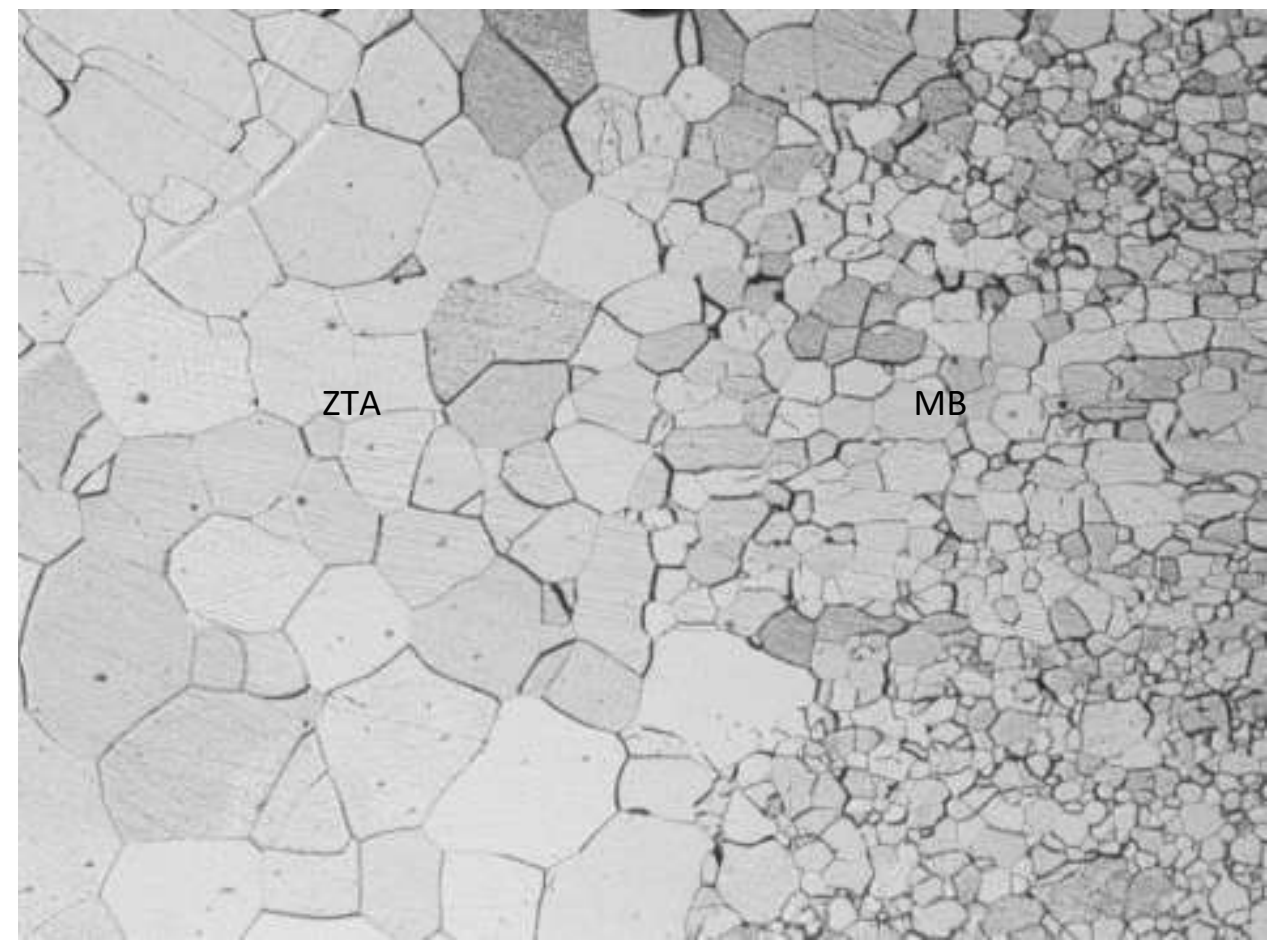

f)

Figura 3 - AISI 409: a) Região de transição entre ZF e ZTA, monoestabilizado 50x; b) Região de transição entre ZF e ZTA, biestabilizado 50x; c) ZF monoestabilizado 50x; d) ZF biestabilizado 50x; e) ZTA monoestabilizado 100x; f) ZTA biestabilizado 100x. Reagente Vilella. 


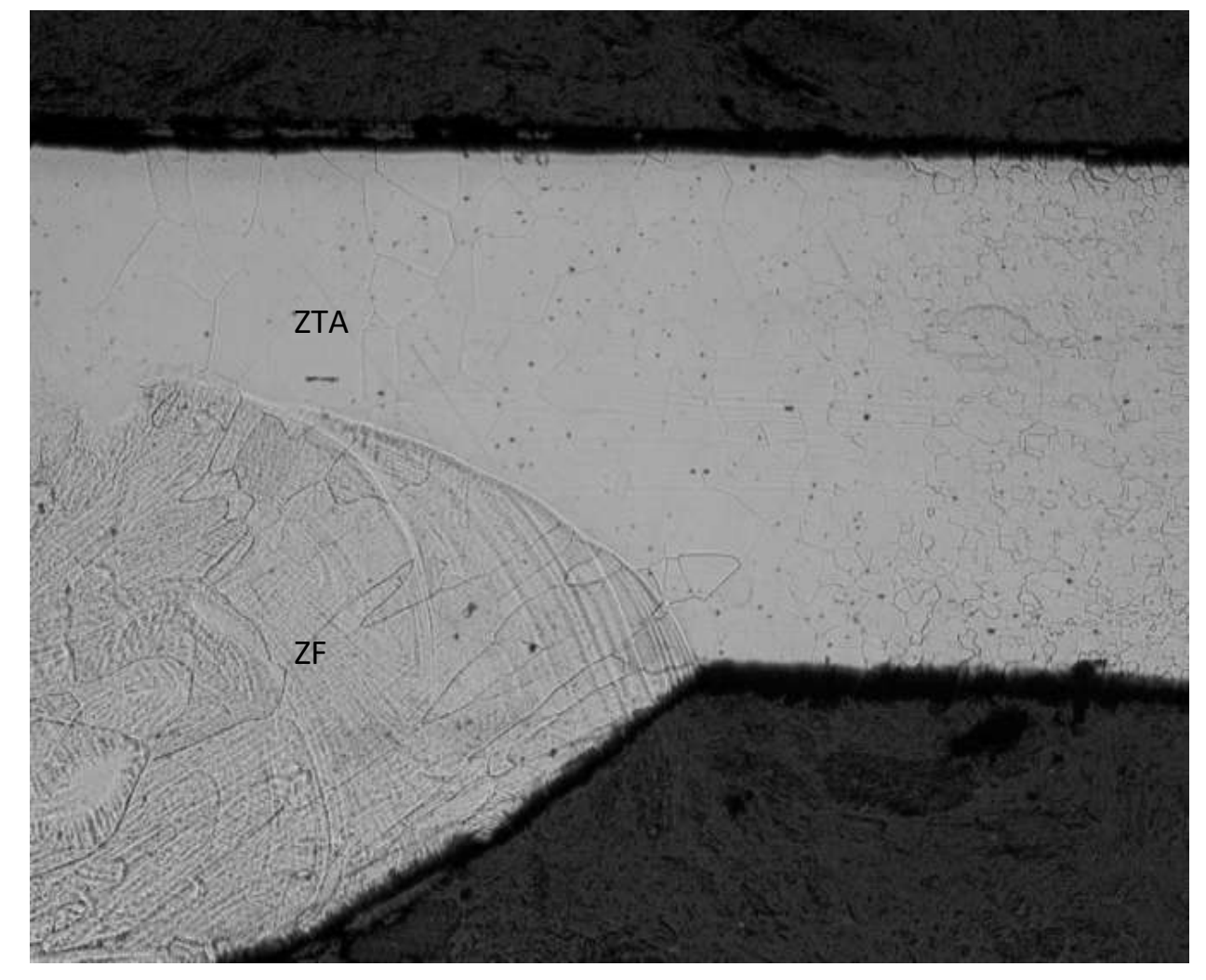

a)

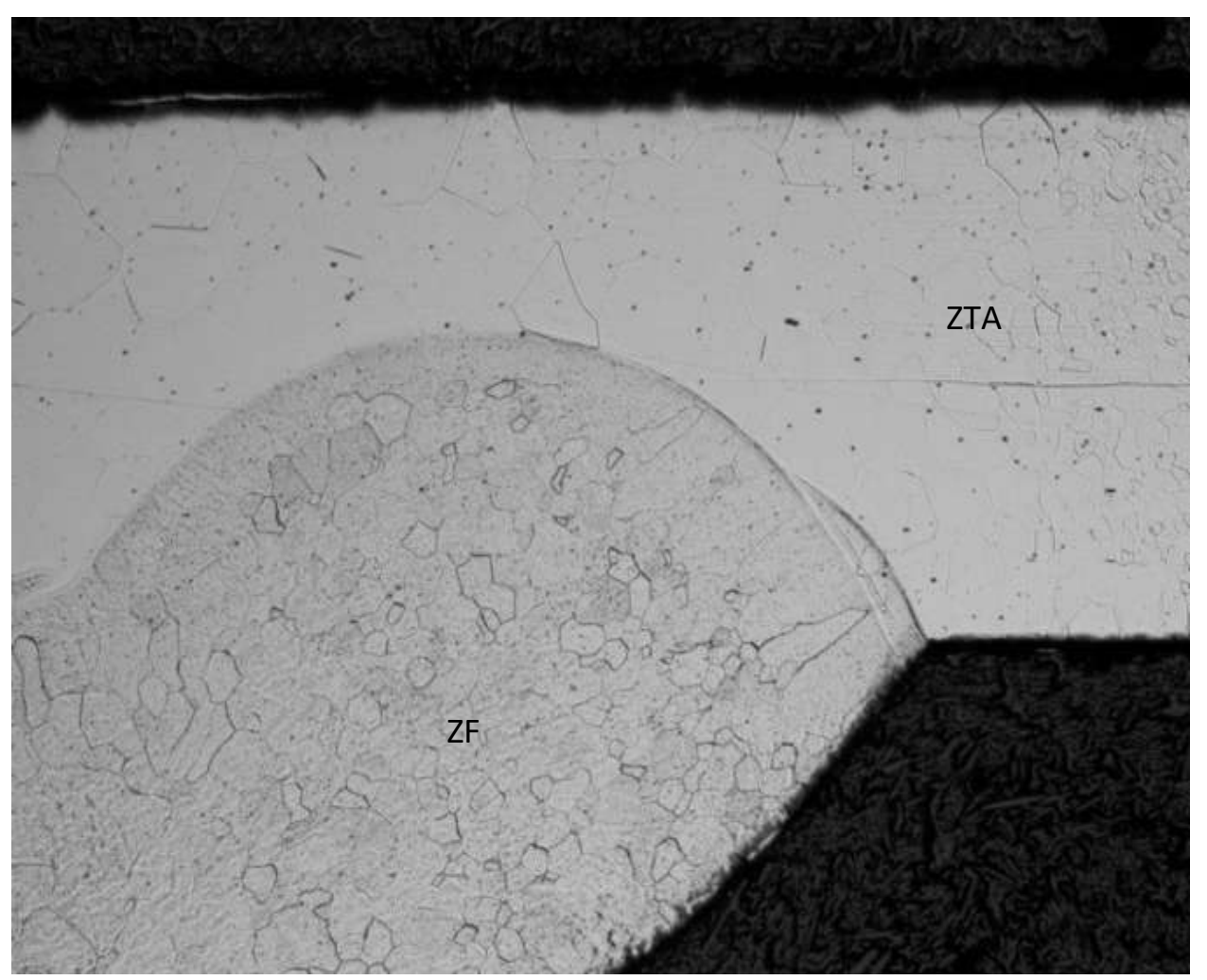

b) 


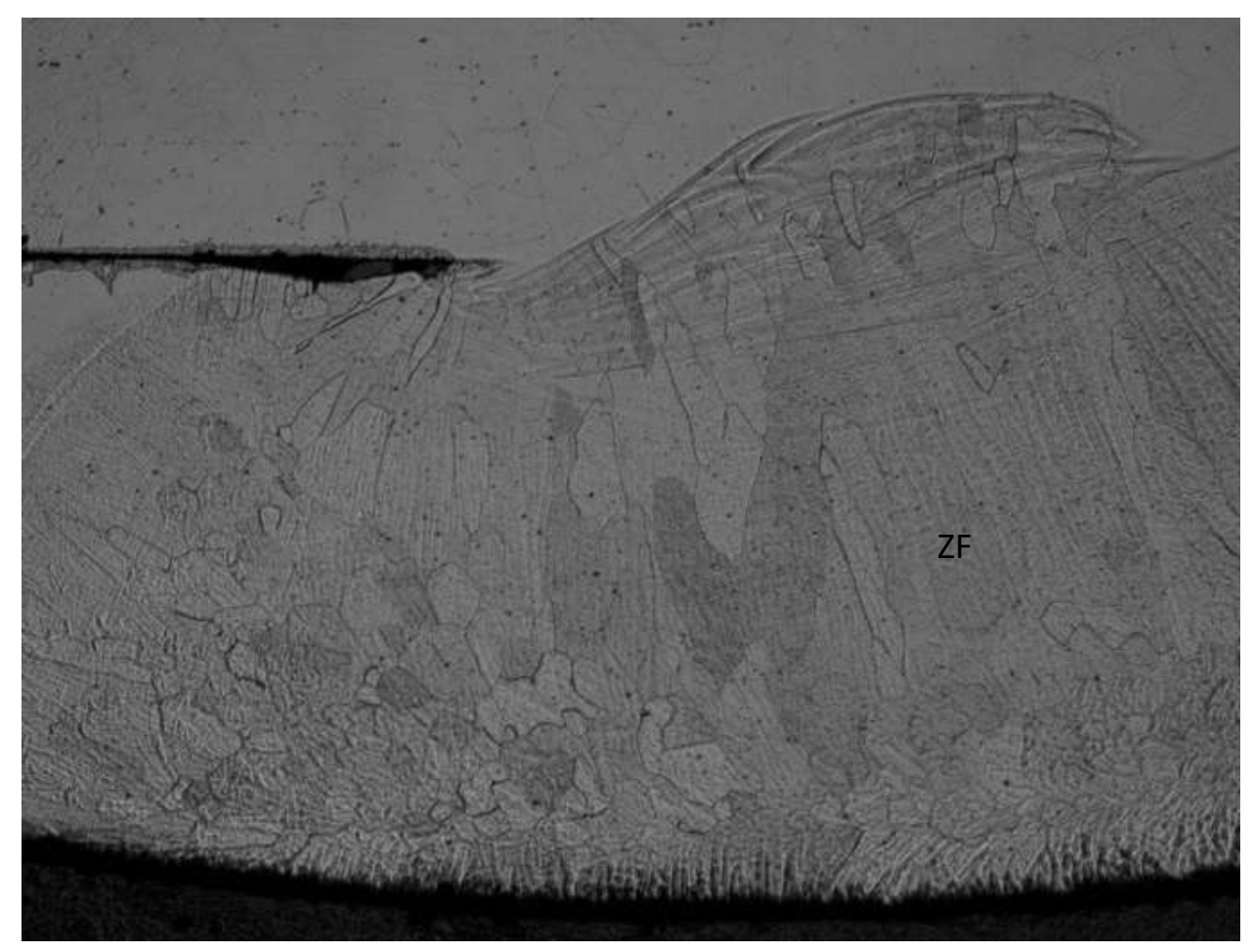

c)

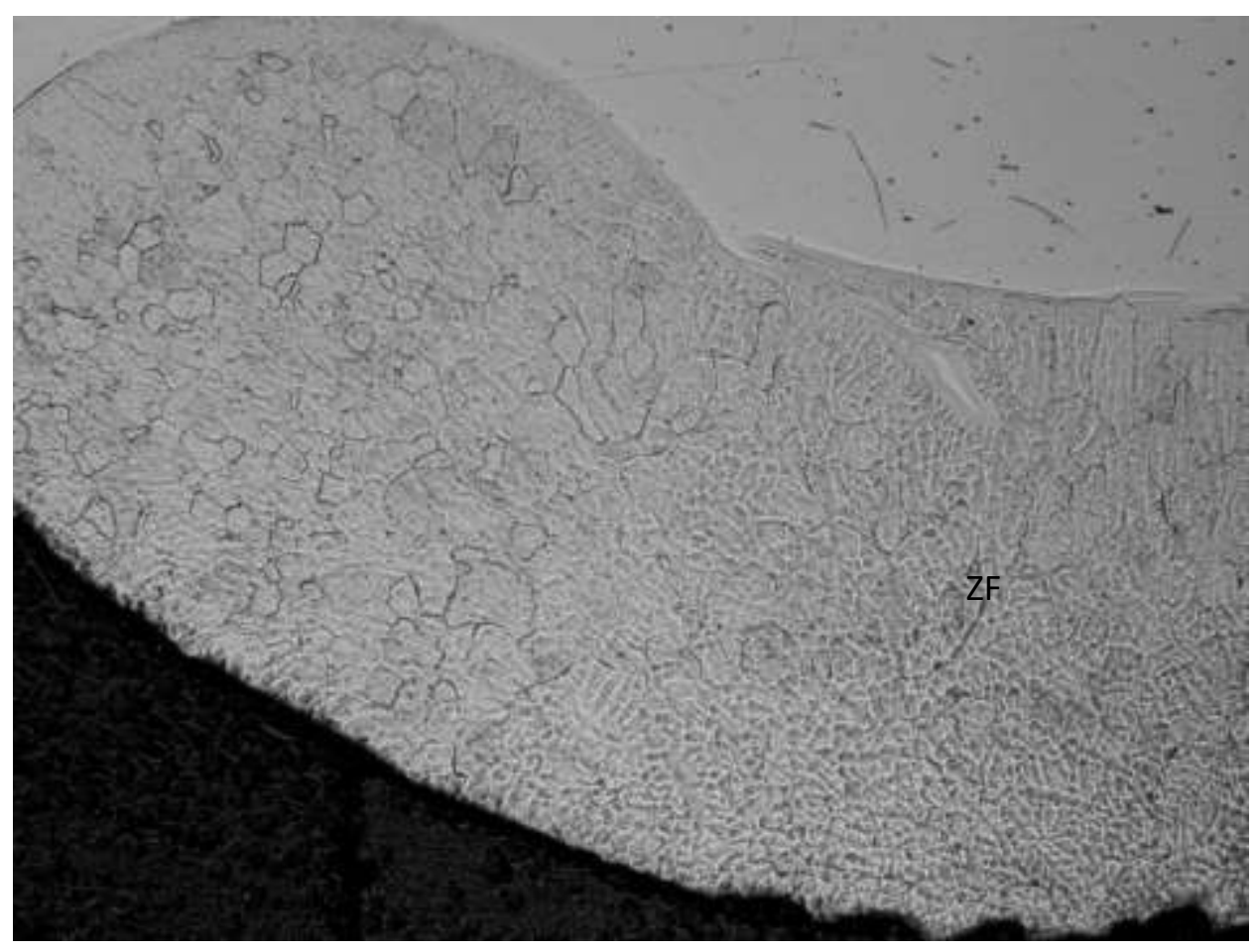

d) 


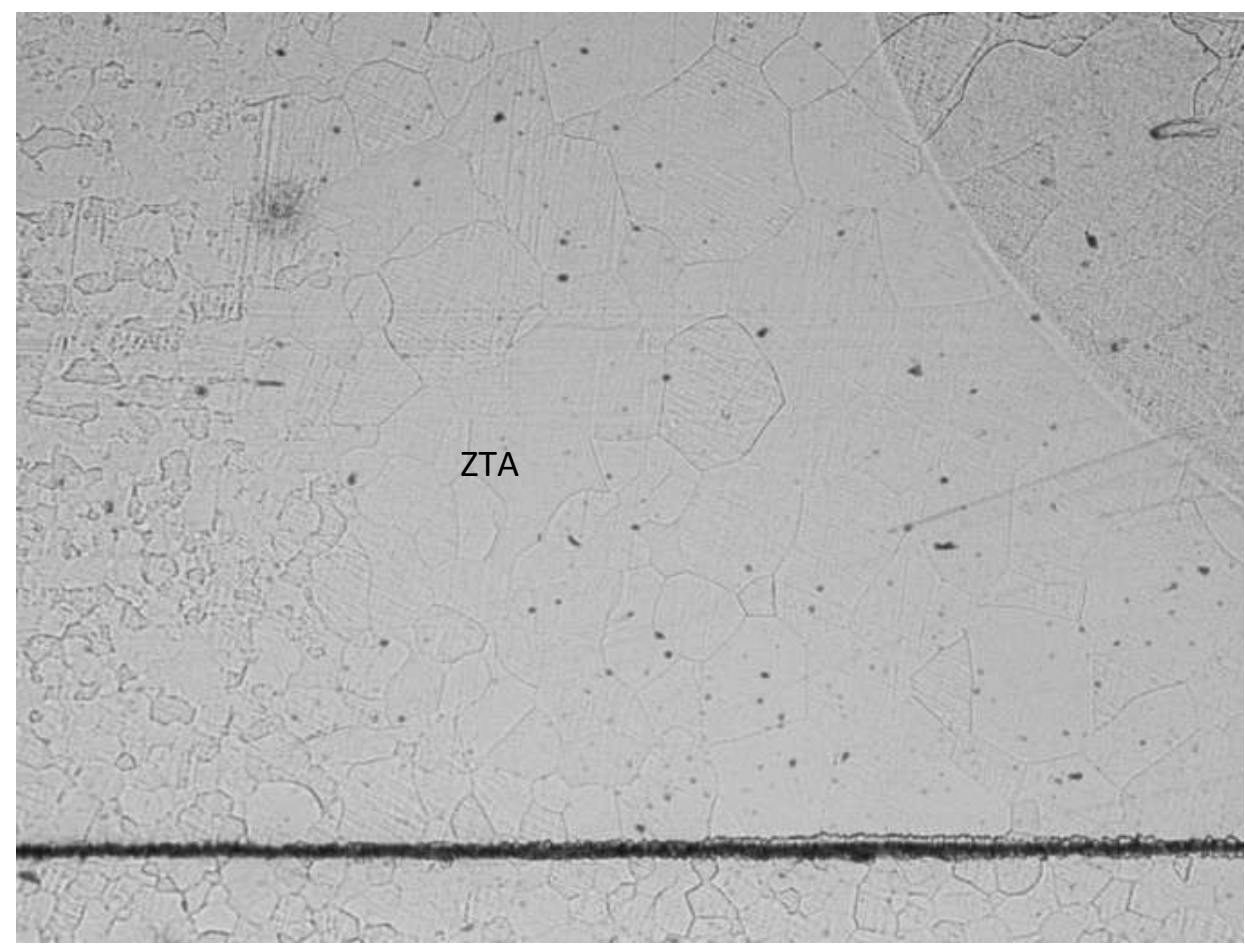

e)

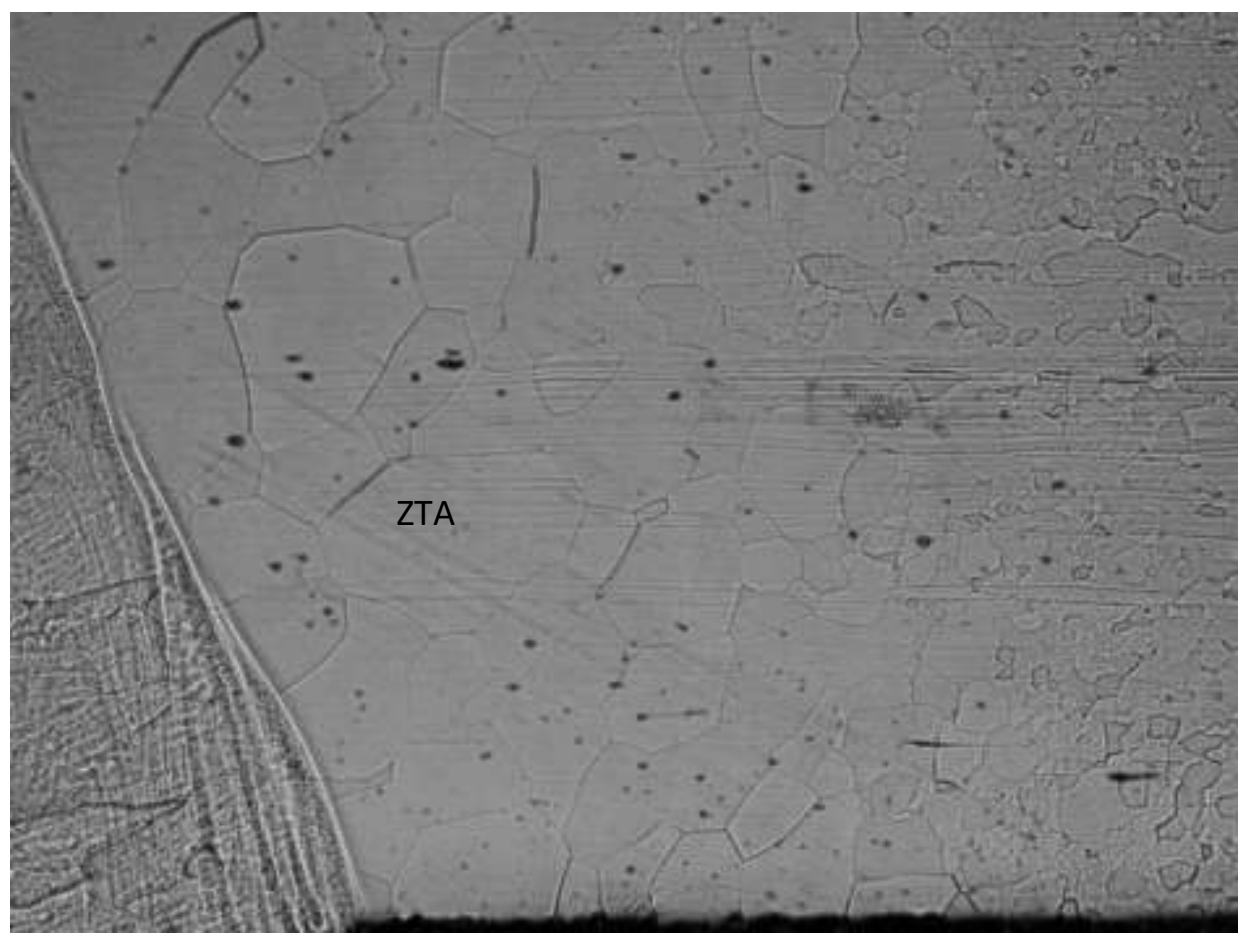

f)

Figura 4 - AISI 409: a) Região de transição entre ZF e ZTA, monoestabilizado 50x; b) Região de transição entre ZF e ZTA, biestabilizado 50x; c) ZF AISI monoestabilizado 50x; d) ZF biestabilizado 50x; e) ZTA monoestabilizado 100x; f) ZTA biestabilizado 100x. Reagente: ácido oxálico. 
A precipitação de fases secundárias, preferencialmente em contornos de grão, apresenta-se mais intensa nas amostras soldadas com arame biestabilizado, Figura 3f. Deve-se destacar, no entanto, que esta amostra foi atacada com reagente Vilella não sendo característica de suscetibilidade a corrosão intergranular.

Pode-se observar na Figura 4 que não houve formação de ditches e/ou valas em nenhuma das amostras soldadas, tanto na região fundida quanto na zona termicamente afetada. Tanto as amostras soldadas com arame monoestabilizado quanto biestabilizado obtiveram bom desempenho na análise de sensitização dos contornos do grão, em nenhum caso observou-se suscetibilidade à corrosão intergranular.

Na Tabela 5 são apresentados os resultados dos ensaios de tração.

Tabela 5 - Propriedades mecânicas das juntas soldadas

\begin{tabular}{|c|c|c|}
\hline Tipo de solda & $\begin{array}{c}\text { Limite de } \\
\text { resistência a tração } \\
{[M P a]}\end{array}$ & $\begin{array}{c}\text { Desvio padrão } \\
{[M P a]}\end{array}$ \\
\hline Arame monoestabilizado & 429,33 & 13,14 \\
\hline Arame biestabilizado & 436,59 & 15,10 \\
\hline
\end{tabular}

Os ensaios de tração comprovaram que a solda não interferiu nas características mecânicas do material, tendo em vista que os valores do limite de resistência se mantem iguais aos do metal base, uma vez que a ruptura das amostras ocorreu no metal base, longe da zona termicamente afetada.

Apesar dos grãos mais grosseiros resultarem em menor dureza e resistência mecânica da amostra, a falha se da no material base AISI 409, isso significa que a junta soldada com arame monoestabilizado, apesar de apresentar menor limite de resistência que a biestabilizada, ainda possui este limite maior que o do metal base. No entanto, deve-se considerar que o aumento no tamanho de grão resulta em diminuição da tenacidade que não foi analisada nesse trabalho.

\section{CONCLUSÃO}

Pode-se concluir que tanto as juntas soldadas com arame monoestabilizado quanto biestabilizado obtiveram bons resultados nos ensaios metalográficos, não apresentando precipitação de fases importante.

Quanto aos ensaios mecânicos, as amostras romperam no metal base longe da zona termicamente afetada mantendo o limite de resistência do material inalterado.

As amostras soldadas com arame monoestabilizado apresentaram aumento do tamanho de grão tanto na zona termicamente afetada quanto na zona fundida, sendo que o aumento no tamanho de grão resulta em diminuição da tenacidade, ensaio que não foi realizado nesse 
trabalho. Grãos mais finos foram observados na solda biestabilizada, característica conferida pelo $\mathrm{Nb}$ na microestrutura, devido sua capacidade de conter o tamanho do grão.

Quanto a suscetibilidade a corrosão intergranular, pode-se observar que em ambas as condições de soldagem, com arame tubular monoestabilizado e biestabilizado, não houve sensitização das amostras. Possivelmente, apenas a monoestabilização já seria suficiente para evitar a sensitização na soldagem causada pela formação de carbonetos e nitretos de cromo no contorno do grão.

\section{REFERÊNCIAS}

${ }^{[1]}$ FARIA, RICARDO AUGUSTO; Efeito dos elementos Ti e Nb no comportamento em fadiga de aços inoxidáveis ferríticos utilizados no sistema de exaustão de veículos automotores. Ouro Preto, Brasil, 2006.

[2] William D. Callister, Jr., David G. Rethwisch. Ciência e engenharia de materiais uma introdução, 8 a edição, 2012.

[3] CES EDUPACK 2015; Martensitic stainless steel, Austenitic stainless steel, Ferritic stainless steel.

${ }^{[4]}$ GORDON , W., VAN BENNEKOM, A. Review of stabilization of ferritic stainless steels. Materials Science and Technology, v. 12, n. 2, p. 126-131, 1996.

${ }^{[5]}$ Ferreira Filho, Demostenes. Influência do gás de proteção na soldabilidade do aço inoxidável ferrítico aplicado a sistemas de exaustores automotivos. Universidade federal de Uberlândia. 2010.

${ }^{[6]}$ Mondenesi, P. J.; Marques, P.V.; Bracarense;A.Q. Soldagem fundamentos e tecnologia, Editora: UFMG, 2005.

${ }^{[7]}$ K.F. Krysiak, J.F. Grubb, B. Pollard, R.D. Campbell. ASM Metals Handbook, Welding, Brazing, and Soldering, Materials Park, Ohio,Volume 6, 2005.

${ }^{[8]}$ DAVIS, J. R. Stainless Steels. Materials Park, ASM International Handbook Comitee, p.3-5 e $445-446,1994$.

${ }^{[9]}$ LULA, R.A.; LENA, A. J., KIEFER, G. C. Intergranular corrosion of ferritic stainless steels. Transactions of ASM, v.46, p. 197-223, 1954.

${ }^{[10]}$ BOND, A. P. Mechanisms of intergranular corrosion in ferritic stainless steels. Transaction of the Metallurgical Society of AIME, v. 245, p. 2127-2134, outubro, 1969.

${ }^{[11]}$ ASTM A763 - 14 - Standard Practices for Detecting Susceptibility to Intergranular Attack in Ferritic Stainless Steels, United States, 2014. 
${ }^{[12]}$ ASTM A370 11a - Standard Test Methods and Definitions for Mechanical Testing of Steel Products. 